\title{
UJI AKTIVITAS ANTIOKSIDAN EKSTRAK BUAH PURNAJIWA (Kopsia arborea Blume.) DENGAN BERBAGAI PELARUT
}

\section{[Antioxidant Activity Test of Purnajiwa (Kopsia arborea Blume.) Fruit Extract With Various Solvents]}

\author{
Didit Purwanto $^{1^{\star}}$, Syaiful Bahri ${ }^{1}$, Ahmad Ridhay ${ }^{1}$ \\ 1) Jurusan Kimia, Fakultas MIPA, Universitas Tadulako \\ Jl. Soekarno Hatta, Kampus Bumi Tadulako Tondo Palu, Telp. 0451- 422611
}

Diterima 13 Desember 2016, Disetujui 22 Januari 2017

\begin{abstract}
Antioxidant activity of Purnajiwa (Kopsia arborea Blume.) fruit has been investigated.The fruit was extracted by various solvents such as n-hexane, ethyl acetate, and ethanol. The aim of the research is to define a class of compounds and antioxidant activity. The compounds test was conducted by the phytochemical method. The results showed that the purnajiwa fruit extract is classified as secondary metabolites of flavonoids, saponins, tannins, alkaloids, and steroids. The antioxidant activity was tested by DPPH method and the amount of antioxidant activity was characterized by $\mathrm{IC}_{50}$ values. The result indicated that the antioxidant activity $\left(\mathrm{IC}_{50}\right)$ for $\mathrm{n}$-hexane, ethyl acetate, and ethanol solvents is 3524.05 ppm, 316.09 ppm, and 154.89 ppm respectively.
\end{abstract}

Keywords: Purnajiwa Fruit, Antioxidant, DPPH, Phytochemicals

\begin{abstract}
ABSTRAK
Telah dilakukan penelitian tentang uji aktivitas antioksidan ekstrak buah purnajiwa (Kopsia arborea Blume.) dengan berbagai pelarut, yaitu $n$-heksan, etil asetat dan etanol. Tujuannya adalah untuk menentukan kelompok senyawa dan aktivitas antioksidannya. Uji kelompok senyawa dilakukan dengan metode fitokimia. Hasil uji menunjukkan bahwa dalam ekstrak buah purnajiwa terdapat senyawa metabolit sekunder dari jenis senyawa flavonoid, saponin, tanin, alkaloid dan steroid. Uji aktivitas antioksidan dilakukan dengan menggunakan metode DPPH dan besarnya aktivitas antioksidan ditandai dengan nilai $\mathrm{IC}_{50}$. Aktivitas antioksidan $\left(\mathrm{IC}_{50}\right)$ berdasarkan tiga jenis pelarut yang digunakan untuk mengekstrak yaitu $n$-heksan, etil asetat, dan etanol masing-masing adalah 3524,05 ppm, 316,09 ppm dan 154,89 ppm.
\end{abstract}

Kata Kunci: Buah Purnajiwa, Antikoksidan, DPPH, Fitokimia 


\section{LATAR BELAKANG}

Senyawa antioksidan semakin berkembang pemanfaatannya pada bidang pangan dan kesehatan. Pada bidang pangan antioksidan dapat berperan sebagai bahan pengawet. Selain itu, dalam bidang kesehatan senyawa antioksidan juga memiliki peranan yang sangat penting. Senyawa antioksidan telah dibuktikan secara ilmiah untuk mengurangi resiko penyakit-penyakit kronis, seperti kanker dan jantung koroner. Mekanisme kerja senyawa antioksidan dalam mencegah penyakit kronis tersebut adalah dengan cara menangkap radikal bebas dalam tubuh (Prakash, 2001). Senyawa antioksidan banyak ditemukan pada tumbuhan, baik pada bunga, daun maupun buah. Tumbuhan yang mengandung senyawa bioaktif seperti flavonoid, alkaloid, dan terpenoid merupakan bahan baku yang potensial yang dapat digunakan sebagai antioksidan alami. Purnajiwa adalah salah satu jenis tumbuhan yang cukup berpotensi mengandung senyawa antioksidan.

Tumbuhan purnajiwa (Kopsia arborea Blume.) merupakan salah satu jenis tumbuhan dari keluarga apocynaceae yang berpotensi sebagai sumber antioksidan alami. Penelitian yang dilakukan oleh Lim \& Kam (2008) terhadap tumbuhan purnajiwa (Kopsia arborea Blume.) mengidentifikasi bahwa di dalam daun tumbuhan tersebut mengandung senyawa golongan alkaloid.
Ekstrak tersebut setelah dilakukan uji, ternyata memiliki daya sitotoksik dengan nilai LC $_{50}$ sebesar $330,58 \mu \quad \mathrm{g} / \mathrm{ml}$ (Kurniawan, 1999).

Berdasarkan teori yang diungkapkan oleh Linnaeus pada abad ke-18 yang menyatakan bahwa tumbuhan yang mempunyai persamaan ciri-ciri morfologi pada umumnya juga mempunyai kandungan yang mirip (Hegnauer dalam Kurniawan, 1999). Uji aktivitas antioksidan terhadap tumbuhan keluarga apocynaceae telah dilakukan oleh Rattanapan et al., (2012) menyatakan bahwa aktivitas antioksidan terbaik dari ekstrak tangkai pulasari (Alyxia reinwardtii) memiliki nilai $I_{50}$ sebesar 53,20 ppm yang merupakan senyawa zhebeiresinol. Hasil penelitian Siham et al., (2014) menyatakan bahwa pada fraksi metanol, $n$-butanol dan rebusan ekstrak daun Nerium oleander memiliki aktivitas antioksidan dengan nilai $\mathrm{IC}_{50}$ masingmasing 5 ppm, 18,00 ppm dan 5,00 ppm. Serta hasil penelitian yang dilakukan oleh Rahman et al., (2014) diperoleh aktivitas antioksidan ekstrak metanol bunga Plumeria alba L. dan Plumeria rubra L. dengan nilai $\mathrm{IC}_{50}$ masing-masing 173,90 ppm dan 167,30 ppm. Kesamaan ciri morfologi dengan tumbuhan tersebut, maka diduga ekstrak purnajiwa (Kopsia arborea Blume.) berpotensi memiliki aktivitas antioksidan.

Pada proses ekstraksi senyawa metabolit sekunder, jenis dan mutu pelarut yang digunakan menentukan senyawa 
apa yang terekstrak. Jenis pelarut dipilih berdasarkan sifat kepolaran senyawa metabolit sekunder, yaitu senyawa polar akan larut dalam pelarut polar, misalnya air dan pelarut non-polar melarutkan senyawa non-polar, misalnya $n$-heksana dan eter (Gritter dalam Putranti, 2013). Hasil uji aktivitas antioksidan yang dilakukan oleh Lisnawati (2014), menunjukkan bahwa tingkat kepolaran pelarut sangat berpengaruh terhadap aktivitas antioksidan yang diperoleh. Aktivitas antioksidan tertinggi diperoleh dari ekstraksi menggunakan pelarut polar $(85,95 \%)$, semi polar $(74,49 \%)$ dan pelarut non polar $(51,82 \%)$. Berdasarkan data tersebut, dalam penelitian inidigunakan pelarut pelarut etanol, etil asetat dan $n$ heksan.

\section{METODE PENELITIAN}

\section{Bahan dan Peralatan}

Bahan yang digunakan dalam penelitian ini adalah buah Purnajiwa masak berwarna ungu kehitaman yang diperoleh dari Kecamatan Sausu, Kabupaten Parigi Moutong. Bahan lain sebagai bahan pengekstrak dan bahan kimia untuk analisis yaitu $n$-heksan teknis, etil asetat teknis, etanol teknis, $\mathrm{HCl}$ pekat, $\mathrm{H}_{2} \mathrm{SO}_{4}$ pekat, serbuk magnesium, anhidrida asetat, klorofom, $\mathrm{FeCl}_{3} 5 \%$, $\mathrm{DPPH}$, vitamin $\mathrm{C}$, aluminium foil, tisu, dan kertas saring.

Peralatan yang digunakan terdiri atas blender, ayakan 60 mesh, talam aluminium, neraca analitik, rotary evaporator, pipet volum, sendok zat, cawan petri, corong kaca, gelas kimia, gelas ukur, spektrofotometri UV-Vis ( UNICO 1100 RS Spectrofotometer), kuvet, dan alat-alat gelas yang umum digunakan dalam laboratorium kimia.

\section{Prosedur Penelitian}

\section{Pengolahan Buah Purnajiwa}

Buah purnajiwa yang diperoleh dipisahkan dari bijinya, kemudian diiris tipis-tipis dan dikering anginkan. Setelah kering, buah purnajiwa yang telah di irisiris dihaluskan menggunakan blender dan di ayak dengan ayakan 60 mesh, tepung kemudian disimpan untuk digunakan pada prosedur selanjutnya.

\section{Ekstraksi Tepung Buah Purnajiwa dengan Berbagai Pelarut}

Tepung buah purnajiwa sebanyak 50 gram ditambahkan $500 \mathrm{ml}$ pelarut $n$ heksan, kemudian dibiarkan selama 48 jam. Setelah itu filtratnya dipisahkan. Perlakuan ini dilakukan sebanyak 3 kali pengulangan. Kemudian residu dikeringkan dan diekstrak kembali dengan $500 \mathrm{ml}$ pelarut etil asetat dan dibiarkan selama 48 jam, selanjutnya filtrat dipisahkan. Perlakuan ini dilakukan sebanyak 3 kali pengulangan. Residu kembali dikeringkan dan diekstrak dengan $500 \mathrm{ml}$ pelarut etanol dan dibiarkan selama 48 jam, lalu filtrat dipisahkan. Perlakuan ini dilakukan sebanyak 3 kali pengulangan.Masing-masing filtrat yang diperoleh kemudian dipekatkan dengan menggunakan rotary vakum evaporator. 


\section{Uji Fitokimia}

a. Uji Flavonoid (Harborne, 1987)

Sebanyak $1 \mathrm{ml}$ sampel ditambahkan 0,5 gram serbuk magnesium dan 10 tetes $\mathrm{HCl}$ pekat (pereaksi shinoda), bila bereaksi positif akan menghasilkan larutan berwarna jingga, merah muda atau merah.

\section{b. Uji Saponin (Depkes RI, 1995)}

Memasukan $1 \mathrm{~mL}$ sampel kedalam tabung reaksi tambahkan dengan $10 \mathrm{~mL}$ air lalu panaskan selama 2-3 menit. Kemudian dinginkan, setelah dingin kocok dengan kuat selama 10 detik. Adanya saponin ditunjukkan dengan terbentuknya buih yang mantap selama tidak kurang 10 menit setinggi 1-10 cm dan pada penambahan $\mathrm{HCl} 2 \mathrm{~N}$ buih akan hilang.

\section{c. Uji Tannin (Harborne, 1987)}

Untuk uji tanin, sebanyak $1 \mathrm{ml}$ sampel ditambahkan beberapa larutan $\mathrm{FeCl}_{3} 5 \%$ bila bereaksi positif akan menghasilkan warna hijau, merah, ungu, biru atau hitam yang kuat.

\section{d. Uji Alkaloid (Harborne, 1987)}

Memasukan 1,0 $\mathrm{mL}$ sampel kedalam tabung reaksi lalu ditambahkan 2-3 tetes pereaksi dragendorf, bila bereaksi positif akan menghasilkan endapan merah jingga.

\section{e. Uji Steroid dan Triterpenoid}

Masukan $1 \mathrm{~mL}$ sampel ke dalam tabung reaksi lalu tambahkan $2 \mathrm{~mL}$ kloroform ditambahkan 10 tetes anhidra asetat dan 3 tetes asam sulfat pekat (reaksi Lieberman-Burchad). Reaksi positif adanya steroid ditunjukkan dengan terbentuknya larutan berwarna biru dan terbentuknya warna merah jingga atau ungu untuk positif adanya terpenoid.

\section{Pembuatan Larutan Ekstrak pada Berbagai Konsentrasi}

Masing-masing ekstrak n-heksan, etil asetat dan etanol ditimbang sebanyak $25 \mathrm{mg}$ dan dimasukan ke dalam labu ukur $25 \mathrm{~mL}$, kemudian dilarutkan dengan pelarut etanol dan ditepatkan volumenya menjadi $25 \mathrm{~mL}$.

Selanjutnya ambil masing-masing larutan ekstrak tersebut sebanyak $1 \mathrm{~mL}, 3$ $\mathrm{mL}, 5 \mathrm{~mL}, 7 \mathrm{~mL}$, dan $9 \mathrm{~mL}$, lalu diencerkan kembali dalam labu ukur 100 $\mathrm{mL}$ sehingga diperoleh larutan ekstrak dengan konsentrasi 10 ppm, 30 ppm, 50 ppm, 70 ppm dan 90 ppm.

\section{Pembuatan Larutan DPPH 50 $\mu \mathrm{M}$}

Ditimbang sebanyak 1,97 mg DPPH dan dimasukkan ke dalam labu ukur 100 $\mathrm{mL}$, kemudian dilarutkan menggunakan pelarut etanol dan ditepatkan volumenya hingga tanda batas. Selanjutnya ukur panjang gelombang maksimum DPPH mulai dari $450 \mathrm{~nm}-550 \mathrm{~nm}$.

\section{Pembuatan Larutan Vitamin C}

Ditimbang sebanyak $2,5 \mathrm{mg}$ asam askorbat dan dimasukkan ke dalam labu ukur $25 \mathrm{~mL}$, kemudian dilarutkan dengan menggunakan etanol dan ditepatkan volumenya hingga tanda batas. Selanjutnya, ambil masing-masing larutan tersebut sebanyak $1 \mathrm{~mL}, 1,5 \mathrm{~mL}, 2 \mathrm{~mL}$, $2,5 \mathrm{~mL}$, dan $3 \mathrm{~mL}$, lalu diencerkan kembali dengan etanol dalam labu ukur $50 \mathrm{~mL}$ sehingga diperoleh larutan ekstrak dengan 
konsentrasi 2 ppm, 3 ppm, 4 ppm, 5 ppm dan 6 ppm.

\section{Uji Aktivitas Antioksidan Dengan Metode DPPH (Pratiwi et al., 2010)}

Untuk penentuan aktivitas antioksidan, masing-masing sampel dengan berbagai konsentrasi dipipet sebanyak 0,2 $\mathrm{mL}$ dengan pipet mikro dan masukan ke dalam vial, kemudian tambahkan 3,8 mL larutan DPPH $50 \mu \mathrm{M}$. Kocok campuran hingga homogen dan dibiarkan selama 30 menit ditempat gelap, ukur serapannya dengan spektrofotometri UV-Vis pada panjang gelombang maksimum DPPH. Aktivitas antioksidan sampel oleh besarnya hambatan serapan radikal DPPH dapat diketahui melalui perhitungan persentase inhibisi serapan DPPH dengan menggunakan rumus :

$\%$ Inhibisi $=\frac{\text { Abs. blanko-Abs. sampel }}{\text { Abs. blanko }} \times 100 \%$

Keterangan:

Abs. Blanko = Absorban DPPH $50 \mu \mathrm{M}$ Abs. Sampel= Absorbansi Sampel Uji

Aktivitas antioksidan ditentukan dengan menggunakan nilai $\mathrm{IC}_{50}$ (Inhibition Concentration $50 \%$ ). $I_{50}$ adalah bilangan yang menunjukkan konsentrasi ekstrak yang mampu menghambat aktivitas suatu radikal sebesar $50 \%$. Nilai $I_{50}$ masingmasing konsentrasi sampel dihitung dengan menggunakan rumus persamaan regresi linier, yang menyatakan hubungan antara konsentrasi fraksi antioksidan yang dinyatakan sebagai sumbu $\mathrm{x}$ dengan $\%$ inhibisi yang dinyatakan sebagai sumbu y dari seri replikasi pengukuran.

\section{HASIL DAN PEMBAHASAN}

\section{Hasil Uji Fitokimia}

Uji fitokimia ini bertujuan untuk mengidentifikasi senyawa metabolit sekunder yang terkandung dalam buah purnajiwa berdasarkan jenis pelarut pengekstraknya. Data uji fitokimia ekstrak buah purnajiwa disajikan dalam tabel 1 sebagai berikut :

Tabel 1 Hasil Uji Fitokimia Ekstrak Buah Purnajiwa

\begin{tabular}{lccc}
\hline \multirow{2}{*}{$\begin{array}{c}\text { Golongan } \\
\text { senyawa }\end{array}$} & $n$-heksan & $\begin{array}{c}\text { Etil } \\
\text { asetat }\end{array}$ & Etanol \\
\cline { 2 - 4 } & - & + & + \\
\hline Flavonoid & - & + & + \\
Saponin & - & + & + \\
Tannin & - & + & + \\
Alkaloid & + & - & - \\
Steroid & - & - & - \\
Triterpenoid & & &
\end{tabular}

Uji golongan senyawa dilakukan pada masing-masing ekstrak dengan ditandai adanya perubahan warna sebagai uji positifnya. Reaksi positif yang dimaksud yaitu terjadi perubahan warna pada saat pengujian golongan senyawa flavonoid, tanin, alkaloid, saponin, steroid dan triterpenoid.

Hasil uji golongan senyawa yang diperoleh, diketahui ekstrak buah purnajiwa hasil ekstraksi menggunakan pelarut non-polar ( $n$-heksan) positif teridentifikasi kelompok senyawa steroid, sedangkan hasil ekstraksi menggunakan pelarut semi-polar (etil asetat) dan pelarut polar (etanol) diketahui positif 
teridentifikasi kelompok senyawa flavonoid, saponin, tanin dan polifenol, dan alkaloid. polar.

Berdasarkan hasil yang diperoleh menunjukkan bahwa pada penggunaan pelarut semi polar dan polar lebih banyak teridentifikasi golongan senyawa metabolit sekunder dibandingkan pada penggunaan pelarut $n$-heksan.

\section{Aktivitas Antioksidan Dengan Metode DPPH}

Aktivitas antioksidan ekstrak buah purnajiwa di uji dengan menggunakan metode DPPH dengan spektrofotometri UV-Vis pada panjang gelombang maksimum $517 \mathrm{~nm}$. Besarnya aktivitas antioksidan ditandai dengan nilai $\mathrm{IC}_{50}$, yaitu konsentrasi larutan sampel yang dibutuhkan untuk menghambat $50 \%$ radikal bebas DPPH.

Nilai $\mathrm{IC}_{50}$ pada masing - masing ekstrak dengan pelarut $n$-heksan, etil asetat dan etanol ditentukan dengan menggunakan persamaan regresi linier dari kurva hubungan konsentrasi sampel terhadap persen inhibisi dengan persamaan $Y=a x+b$, konsentrasi sampel (ppm) sebagai sumbu (X) dan nilai persentase inhibisi sebagai sumbu $(Y)$.

Berdasarkan persamaan regresi linier dari Gambar 1, Gambar 2, dan Gambar 3 hubungan antara konsentrasi hasil ekstrak terhadap persentase inhibisi, diperoleh nilai $I_{50}$ berturut-turut yaitu 3524,05 ppm, 316,09 ppm dan 154,89 ppm.

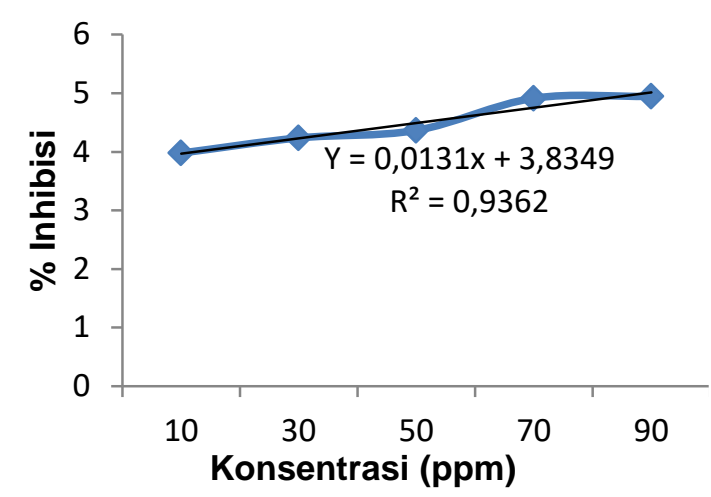

Gambar 1 Kurva Hubungan Konsentrasi Hasil Ekstrak $n$-Heksan Terhadap Persentase Inhibisi.

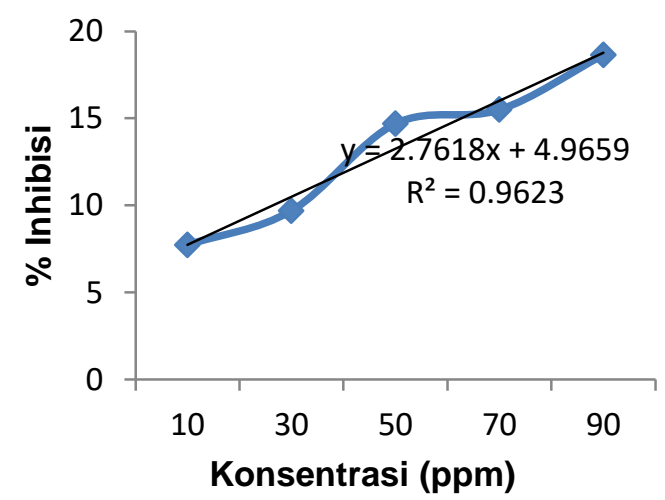

Gambar 2 Kurva Hubungan Konsentrasi Hasil Ekstrak Etil Asetat Terhadap Persentase Inhibisi.

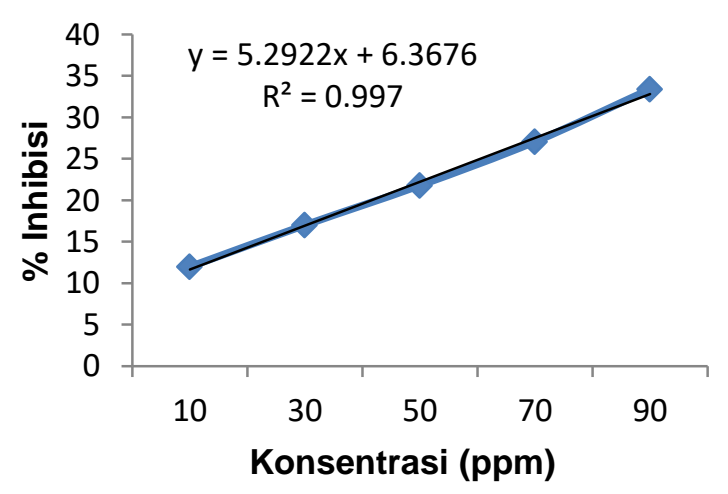

Gambar 3 Kurva Hubungan Konsentrasi Hasil Ekstrak Etanol Terhadap Persentase Inhibisi.

Perbandingan jenis pelarut yang digunakan dalam proses ekstraksi mempengaruhi aktivitas antioksidan yang diperoleh. Berdasarkan pada uji aktivitas antioksidan menunjukkan bahwa 
penggunaan pelarut etanol memberikan nilai $\quad I_{50}$ terkecil (aktivitas tertinggi) dibandingkan pada penggunaan pelarut etil asetat maupun $n$-heksan. Hal ini diduga karena didalam sampel buah purnajiwa banyak terdapat senyawa bioaktif yang bersifat polar jika dibandingkan dengan senyawa bioaktif yang bersifat nonpolar dan semipolar sehingga pelarut polar (etanol) lebih banyak menarik komponen bioaktif yang ada pada buah purnajiwa tersebut.

Adapun sebagai pembanding, dilakukan pengujian aktivitas antioksidan terhadap asam askorbat (vitamin C) dengan masing - masing konsentrasi 2, 3, 4, 5 dan 6 ppm. Persen inhibisi tertinggi untuk asam askorbat adalah 11,69\%. Sedangkan nilai $\mathrm{IC}_{50}$ pada asam askorbat adalah 32,65 ppm.

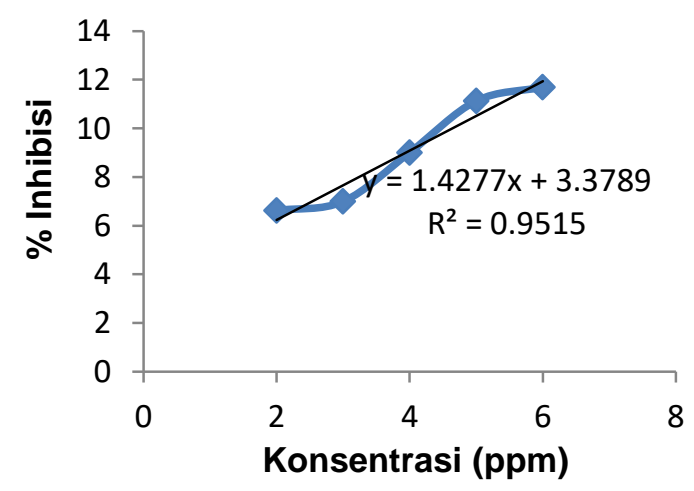

Gambar 4 Kurva Hubungan Konsentrasi Vitamin C Terhadap Persentase Inhibisi.

Bila dibandingkan nilai $\mathrm{IC}_{50}$ pembanding vitamin $\mathrm{C}$ dengan nilai $\mathrm{IC}_{50}$ ekstrak etanol yang diperoleh, diketahui bahwa nilai $\mathrm{IC}_{50}$ asam askorbat lebih tinggi. Hal ini menandakan bahwa sifat antioksidan senyawa bioaktif yang terkandung dalambuah purnajiwa bersifat lemah jika dibandingkan dengan vitamin C.

Aktivitas antioksidan dapat dibagi menjadi kategori sangat kuat, kuat, sedang, lemah, dan sangat lemah (Blois, 1985 dalam Molyneux, 2004)).

Antioksidan dikatakan sangat kuat apabila memiliki nilai $I_{50}$ kurang dari 50 ppm, antioksidan kuat memiliki nilai $\mathrm{IC}_{50}$ berada pada kisaran 50 ppm hingga 100 ppm, antioksidan sedang memiliki nilai $I_{50}$ berkisar antara 100 ppm hingga 150 ppm, antioksidan lemah memiliki kisaran 150 ppm hingga 200 ppm dan nilai $\mathrm{IC}_{50}$ lebih dari 200 ppm merupakan antioksidan berkategori sangat lemah.

Dari hasil pengukuran aktivitas antioksidan ekstrak buah purnajiwa, hasil tersebut lebih lemah bila dibandingkan dengan hasil penelitian terhadap keluarga tumbuhan purnajiwa. Seperti yang dilakukan oleh Rattanapan et al., (2012) yang menemukan aktivitas antioksidan dalam ekstrak tangkai Pulasari yakni sebesar 53,30 ppm. Serta penelitian oleh Siham et al., (2014) yang menemukan aktivitas antioksidan dalam fraksi metanol dan $n$-butanol ekstrak daun Nerium oleander yakni 5,00 ppm dan 18,00 ppm. Namun aktivitas antioksidan ekstrak etanol buah Purnajiwa lebih tinggi dibandingkan aktivitas antioksidan ekstrak metanol bunga Plumeria alba L. dan Plumeria rubra L. yang dilakukan oleh Rahman et al., (2014) yakni 173,90 ppm dan 167,30 ppm. 
Hasil yang diperoleh menunjukkan bahwa semua ekstrak memiliki aktivitas antioksidan baik dari pelarut polar maupun non polar. Perbedaan aktivitas yang diperoleh pada setiap ekstrak tersebut kemungkinan disebabkan adanya perbedaan kandungan dan jumlah senyawa aktif yang terdapat dalam ekstrak, sehingga aktivitas antioksidan yang diperoleh juga berbeda. Ekstrak etanol mempunyai aktivitas antioksidan yang lebih tinggi dibandingkan dengan ekstrak $n$-heksan dan etil asetat, hal ini diduga karena adanya kandungan senyawa aktif dari beberapa golongan senyawa antioksidan yang bersifat polar lebih banyak dibandingkan yang bersifat non polar yang terdapat dalam buah purnajiwa.

\section{KESIMPULAN}

Berdasarkan hasil penelitian yang diperoleh, disimpulkan bahwa senyawa metabolit sekunder yang terdapat dalam buah purnajiwa (Kopsia arborea Blume.) berdasarkan uji fitokimia adalah senyawa flavonoid, saponin, tanin, alkaloid, dan steroid. Aktivitas antioksidan tertinggi yang diperoleh dari ekstrak menggunakan pelarut etanol dengan nilai $\mathrm{IC}_{50}$ sebesar 154,89 ppm, etil asetat dengan nilai $I_{50}$ 316,09 ppm, dan $n$-heksan dengan $I_{50}$ sebesar 3524, 05 ppm.

\section{UCAPAN TERIMA KASIH}

Secara khusus peneliti menyampaikan ucapan terima kasih kepada Laboran Jurusan Kimia FMIPA UNTAD.

\section{DAFTAR PUSTAKA}

Depkes RI. 1995. Farmakope Indonesia Edisi IV. Jakarta: Depertemen Kesehatan RI.

Harborne J. B. 1987. Metode Fitokimia : Penuntun Cara Modern Menganalisis Tumbuhan, Bandung: Institut Teknologi Bandung, (diterjemahkan oleh Kosasih Padmawinata dan Iwang Soediro).

Kurniawan K. 1999. Skrining Fitokimia Terhadap Tumbuhan Suku Apocynaceae Yang Mempunyai Daya Sitotoksik Terbesar Terhadap Artemia salina (Leach), [Skripsi], Surabaya: Fakultas Farmasi Universitas Negeri Surabaya,.

Lim K.H., T.S. Kam. 2008. Methyl chanofruticosinate alkaloids from Kopsia arborea, Phytochemistry, 69: 558-561.

Lisnawati. 2014. Aktivitas Antioksidan Ekstrak Daun Kelor (Moringa olefera L.) dari Berbagaitingkat Kepolaran Pelarut, [Skipsi] Palu: FMIPA Kimia, Universitas Tadulako.

Molyneux P. 2004. The Use Of The Stable Free Radical Diphenylpicrylhydrazyl (DPPH) for Estimating Antioxidant Activity, Songklanakarin J. Sci. Technol. 26 (2): 211-219.

Prakash A. 2001. Antioxidant Activity, Medallion Laboratories: Analytical Progress, 19 (2) : 1-4.

Pratiwi P., M. Suzery, B. Cahyono. 2010. Total Fenolat Dan Flavonoid Dari Ekstrak Dan Fraksi Daun Kumis Kucing (Orthoshipon stamineus B.) Jawa Tengah Serta Aktivitas Antioksidannya, Jurnal Sains \& Matematika, 18 (4) : 140-148.

Putranti R.I. 2013. Skrining Fitokimia Dan Aktivitas Antioksidan Ekstrak Rumput Laut Sargassum duplicatum dan Turbinaria ornata Dari Jepara, 
[Tesis] Semarang: Program Studi Magister Manajemen Sumberdaya Pantai, Fakultas Perikanan Dan IImu Kelautan, Universitas Diponegoro.

Rahman H., V. B. Reddy, S. Ghosh, S. K. Mistry, G. Pant, G. Sibi. 2014. Antioxidant, cytotoxic, and hypolipidemic activities of Plumeria alba L. and Plumeria rubra L., American Journal Of Life Sciences, $2(6-1): 11-15$.

Rattanapan J., J. Sichaem, S. Tip-pyang. 2012. Chemical Constituents And Antioxidant Activity From The Stems Of Alyxia reinwardtii, Academy of Chemistry of Globe Publications, 6 (3) : 288-291.

Siham L., O. Saida, T. Moha, S. Nadia, A. Hakima. 2014. Chemical Analysis and Antioxidant Activity of "Nerium oleander" Leaves, Online Journal of Biological Sciences. 14 (1): 1-7. 